\title{
Analysis of the market of electric tractors in ag- ricultural production
}

\author{
Jacek Caban ${ }^{1, *}$, Jan Vrabel $^{2}$, Branislav Šarkan², Janusz Zarajczyk ${ }^{1}$, Andrzej Marczuk ${ }^{1}$ \\ ${ }^{1}$ University of Life Sciences in Lublin, Faculty of Production Engineering, Głęboka 28, 20-612 \\ Lublin, Poland \\ ${ }^{2}$ University of Žilina, Faculty of Operation and Economics of Transport and Communications, \\ Univerzitna 1, 010 26, Žilina, Slovakia
}

\begin{abstract}
In Poland, the market of electric field tractors is practically non-existent. There are individual models in offers dedicated to the agriculture made by foreign producers. However, these offers are presented mainly at agricultural fairs. The article presents the research on the needs of farms for electric tractors and presents the possibilities of developing electro mobility in this sector of the economy. Questionnaire was presented, data were collected from those working in the agricultural sector. The data will be used to gauge attitudes and opinions towards alternative power systems implemented in agriculture.
\end{abstract}

Keywords: agricultural vehicles, electric drive, electric motors, energy intensity

\section{Introduction}

The reduction of oil sources, the increase of environment pollution and the intensification of climate changes have led the whole world looking for alternative fossil energy sources for more efficient usage [1]. Energy intensity of transport is a current topic around the world [2]. At present, the drives of vehicles use energy that is largely bounded in fossil fuels $[3,4]$. Based on the ever-increasing demands that are placed on each of the transport sector, these resources are gradually depleting and are not unlimited [5-7]. Renewable energy sources in agriculture more and more are being talked about. Incorporation of electric drives in tractor and agricultural machinery presents advantages in terms of increased energy efficiency and expanded functionalities [8]. Possibilities to improve work efficiency and reduce fuel consumption, and thus reduce exhaust emissions from agricultural tractors, were presented in research [9-11]. Magalhaes et al. in the paper [12] described the main researches with proposals to overcome the problems of implementing electric tractors, as supply and electricity storage. They present technical and economic comparisons between conventional tractors with ICE, and moreover electric tractors are discussed. Tomasikova et al. [13] in research work describes modelling and simulation of the vehicle physical model and analysis of transport mechatronic system properties. The model includes also other blocks, which are used to show measured outputs and control blocks, that make the vehicle mechatronic

\footnotetext{
* Corresponding author: jacek.caban@up.lublin.pl

Reviewers: Oleksandr Kravchenko, Dalibor Barta
} 
systems controllable according the driver model inputs [13]. Agricultural technology based on the achievements of the automotive industry and implemented in cars technologies is often used nowadays in agricultural vehicles. Two development trends of agricultural tractors can be seen. One of them is a hybrid drive combining the advantages of an internal combustion engine with electric motors. The second development trend is the production of tractors with purely electric drive. That is why complex technologies used in them justify the cost of the vehicle - in most cases the cost of the hybrid vehicle is two times bigger than that of a conventional vehicle and matches the cost of the electric vehicle. Prototypes of electric machines have been created for several years. Some manufacturers believe that in the future electric tractors will become cheaper than traditional tractors due to environmental requirements, which are becoming stricter. Mcfadzean and Butters [14] reported on the basis of calculations that, the cost of charging an all-electric system capable of producing the required output of the practical tests would be higher than the cost of diesel for the same output. In pursuit to lower the levels of toxic exhausts, Fendt, German manufacturer of agricultural equipment has shown the public on recent Agritechnica fair in Hanover their first electric tractor, model e100 Vario [15]. First examples of e100 Varios are believed to be on the roads - or farms - in the year 2018 [15]. John Deer has been testing prototypes for several years and also has an electric tractor. More details about diesel-electric and electric agricultural tractors we can found in this references [15-17]. We can expect a real war in the market of electric tractors in the coming years. Because investments in electric drive are another natural step among manufacturers.

One of the advantages of the electric drive is, for example, the lack of emissions at the place of use. An electric motor compared to a traditional internal combustion engine generates less vibration and noise. This is a special advantage mainly at night and in the residential area. The electric drive allows, above all, precision in the control of the vehicle. However, the ideal electric tractor, despite many attempts to make and test it, still lies in the sphere of challenges. The main problem that is hindered by is the electrical capacity of the battery, because a few hours of one-time operation is too short for most of the hosts to carry out their field tasks. The necessity of recharging the battery causes a stoppage at work, during which the farmer exposes himself to a waste of time, which is also connected with agrotechnical periods.

In Poland, the market of electric agricultural tractors is practically non-existent. There are individual models in offers dedicated to the agriculture of foreign producers. However, these offers are presented mainly at agricultural fairs. On foreign markets one can meet agricultural machines produced by large concerns equipped with electric drives, such as the Massey Ferguson 9280 Delta combine harvester, Fendt X harvester, CASE IH ProHybrid EECVT tractor, Caterpilar D7WE crawler tractor. In contrast, in the case of passenger cars, every major automotive company currently has such a vehicle produced in series. It is a good prognosis for electric drives to have a significant market share in the future in the agricultural machinery sector as well.

Currently, in Poland, the Energy and Development Departments is working together on the act on electro mobility, which is to regulate the entire market. Pilot projects are being carried out to develop electro mobility in individual voivodships. In the opinion of many experts, electric vehicles can become popular in Poland, if macroeconomic conditions are created for this purpose. This applies not only to the individual vehicle market but also to the public transport buses. Electric vehicles will also be a vital element in future smart urban transport systems [18]. In the case of electric vehicles, energy intensity of traffic constitutes smaller part of the consumed energy than in the case of vehicles with ICE [19]. Fuel savings in hybrid vehicles oscillate between approx. $30 \%$ in comparison with the vehicles with internal combustion engines [20]. 
Another issue is the need to promote and awaken awareness among farmers about the benefits of using electric agricultural tractors. Tax incentives would also encourage farmers to invest in such machines. Undoubtedly, investments in charging infrastructure and tax incentives for zero-emission car buyers are necessary for the development of electro-mobility in Poland. Most authors agree that innovative technologies can effectively facilitate the reduction of emissions and lead to sustainable development [18]. At the same time, technological progress needs to be supplemented by behavioural and cultural changes concerning mobility patterns and preferences [18]. This last issue seems to be the most difficult task.

\section{Agricultural tractors market}

Overall farm tractors market is highly fragmented in nature characterized by more than 300 companies with numerous brands and joint ventures across the globe [21]. Major farm tractor manufacturers have been striving extensively in order to maintain their market position. Entering into joint ventures with local tractor manufacturers has been one of the key strategies adopted by tractor manufacturers from North America and Europe regions [21]. The competition is expected to become more intense with the revival of farm tractors market during the forecast period from 2018 to 2026 according to the research study conducted by Credence Research [21].

This study (Fig. 1) presents the main division due to the tractor's power output without distinguishing the type of drive source. However, the presented graph shows another important part of the market (autonomous tractors). In this segment, the drive sources can be varied, but the electric drive is particularly important, ensuring the perfect precision of vehicle control.

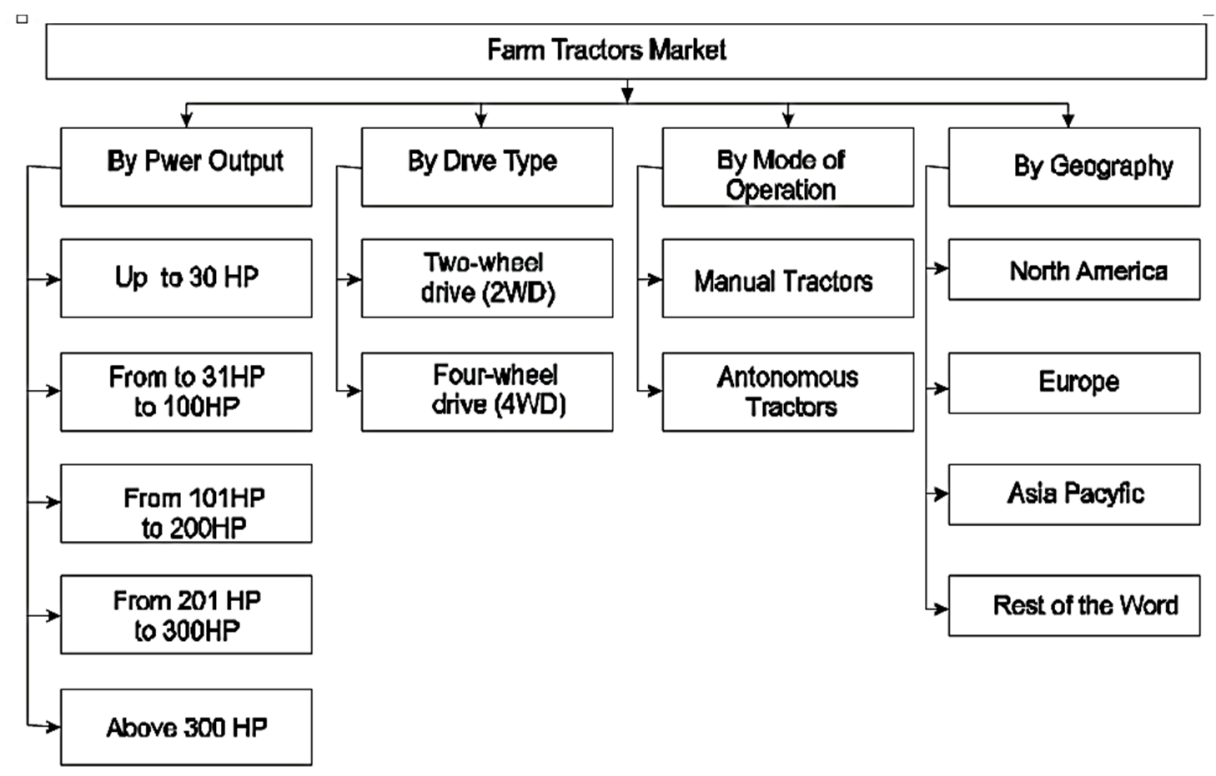

Fig. 1. World agricultural tractors market [21]

In Table 1., structure of the agricultural machinery industry in the European Union in 2014 was presents. 
Table 1. Structure of the agricultural machinery industry in the European Union in 2014 [22]

\begin{tabular}{|c|c|c|c|}
\hline Country & Turnover (€m) & Number of companies & Number of employees \\
\hline Germany & $12,348.7$ & 637 & 40,166 \\
\hline Italy* $^{*}$ & $9,224.4$ & 1,908 & 29,120 \\
\hline France & $5,124.9$ & 589 & 16,806 \\
\hline United Kingdom $^{* *}$ & $2,978.8$ & 478 & 6,362 \\
\hline Nethelads & $2,384.2$ & 337 & 7,400 \\
\hline Belgium & $2,205.5$ & 142 & 4,980 \\
\hline Austria & $2,058.5$ & 116 & 6,271 \\
\hline Poland & $1,748.0$ & 478 & 16,420 \\
\hline Sweden & $1,551.9$ & 200 & 4,527 \\
\hline Spain & $1,370.5$ & 701 & 7,163 \\
\hline Finland & $1,096.5$ & 144 & 4,346 \\
\hline Czech Republic & 693.2 & 291 & 7,405 \\
\hline Denmark & 564.2 & 160 & 3,561 \\
\hline Hungary & 483.4 & 145 & 5,196 \\
\hline Slovakia & 177.7 & 52 & 1,381 \\
\hline Ireland ${ }^{* * *}$ & 147.2 & 36 & 1,051 \\
\hline Slovenia & 146.5 & 59 & 1,201 \\
\hline Portugal & 124.7 & 192 & 1,238 \\
\hline Greece & 103.3 & 358 & 1,661 \\
\hline Romania & 98.5 & 69 & 2,205 \\
\hline Croatia & 91.0 & 58 & 1,098 \\
\hline Estonia & 79.2 & 27 & 648 \\
\hline Bulgaria & 28.7 & 54 & 1,103 \\
\hline Latvia & 27.0 & 21 & 645 \\
\hline Lithuania & 23.3 & 11 & 486 \\
\hline Cyprus & 5.9 & 11 & 55 \\
\hline Luxenburg & 0.0 & 0 & 0 \\
\hline Malta & 0.0 & 0 & 0 \\
\hline Total EU (28) & 44,886 & 7,274 & 172,495 \\
\hline
\end{tabular}

The agricultural machinery sector reveals a highly specialised Europe with 10 countries totalising $80 \%$ of the number of companies and jobs in the manufacturing sector and generating $91 \%$ of turnover in the European Union [22]. The first place in the agricultural machinery industry in the European Union production is taken by Germany with a turnover 
of $€ 12$ bn, and more than 40,000 employees. Second one is Italy with a total of $€ 9$ bn, and 29,000 employed. France is the third producing country with a turnover of $€ 5$ bn, and 16,000 of employees. Poland with the number of 16,000 employees is the fourth country in terms of highest number of employees, but in eight place regarding turnover - $€ 1.74 \mathrm{bn}$, in the agricultural machinery industry in the European Union in 2014 (Table 1.).

Figure 2 presents the European production of agricultural tractors divided by the tractors power between $2007 \div 2014$. European production of agricultural tractors amounted $€ 7.9$ bn in 2014 decreased by $7.9 \%$ compared to 2013 [22]. This reduction affects all power segments. This category represents $25 \%$ of the total value of agricultural machinery produced in Europe [22]. As we can see, the largest production was achieved in 2008 , just before the global banking crisis.

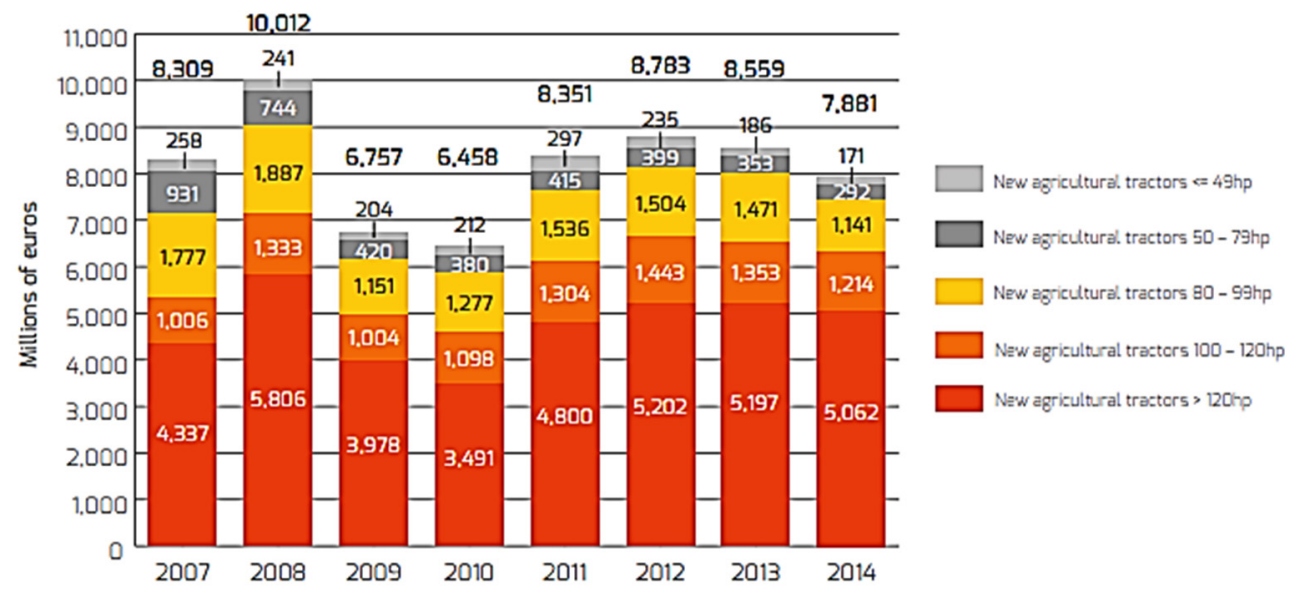

Fig. 2. European production of agricultural tractors [22]

The global agricultural tractors market is trying to recover from its current state of regression with a global market value of US\$ 8.15 bn in 2017 and anticipated to exhibit a growth with a CAGR of $5.7 \%$ from 2018 to 2026 . The global demand for food grains is expected to rise from 3 billion tonnes in 2010 to a staggering 4.5 billion tonnes in 2050 . In 2017, Deere and Co., world's second largest farm equipment and tractor manufacturer (by sales) registered growth in sales in past four years. The aforementioned incidents are clearly highlighting the revival of the tractor market in the following years.

\section{Methodology}

The purpose of the work was to analyse the awareness of farmers and the needs of farms for electric tractors. In addition, a view on the development of electro mobility in Poland was presented. The following research methods were used in the work:

- a questionnaire survey using a paper questionnaire was carried out on 40 farm owners of both sexes, in different age groups,

- analysis of collected data and their presentation by graphical method.

The research part was elaborated on the basis of a survey among farmers in the Lubelskie and Świętokrzyskie voivodships. The survey was conducted on a group of 40 respondents and contained 12 questions with the possibility of single and multiple choice. The respondents participating in the study were of both sexes and belonged to different age categories. Respondents had the opportunity to choose the answers from among the listed 
and one open question, in which the respondents could express their opinion on electric tractors. In addition, the research part includes a presentation of the results of the survey, their analysis, and a summary.

\section{Analysis of the survey results}

The following figures present a graphic interpretation of the results of the survey. Figure 3a) presents the results regarding the age of the respondents, and in Figure $3 \mathrm{~b}$ ) the division by gender. The questionnaire was attended by seven people aged $20 \div 30$, five people between $31 \div 40$, seven people between $41 \div 50$, seventeen people between $51 \div 60$, and four above 61 years. 40 people took part in the study, of which five were women and thirty-five were men.

a)

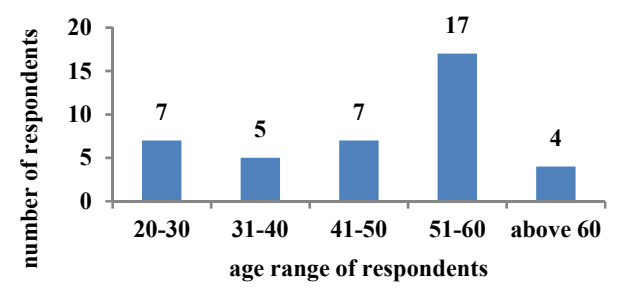

b)

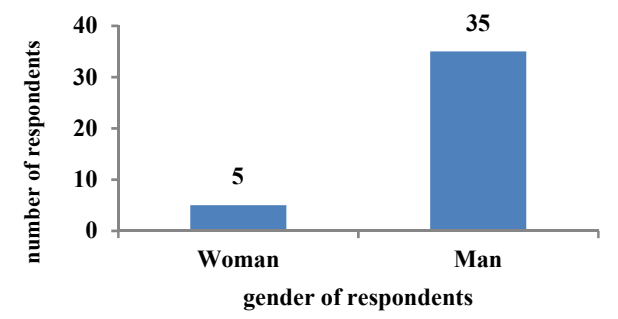

Fig. 3. Share of survey participants relative to: a) Age of respondents, b) Gender of respondents

Figure 4a) shows the type of education held by the respondents. Figure 4b) shows the period of running a farm by respondents expressed in years.

a)

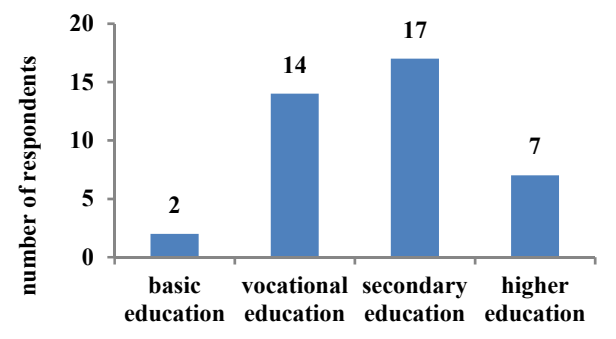

b)

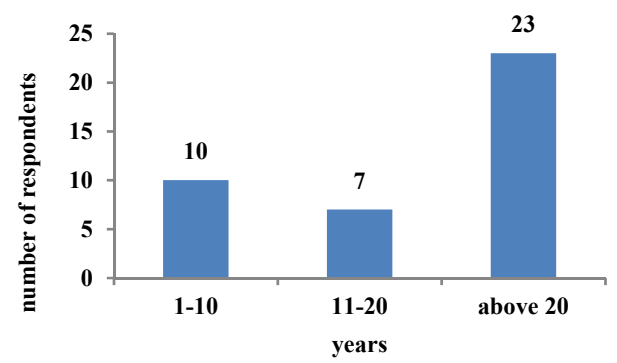

Fig. 4. Share of survey participants relative to: a) Type of education held by the study participants, b) Period of running a farm

As it can be seen in Figure 4a), two of the respondents have basic education, fourteen vocational, seventeen secondary and seven higher. Data analysis regarding the period of activity (Fig. 4b)) is presented as follows: in the $1 \div 10$ year range, the farm is run by ten people, seven in the range of $11 \div 20$ years, and twenty-three people over 20 years.

Figure 5a) presents data on the size of the farm. In turn, Figure 5b) contains data on the production profile of farms run by respondents.

Analysing the data presented in Figure 5a), it can be seen that the largest number of people, thirty two respondents work on the farm of size from $1 \div 30$ ha, five in the range of $31 \div 60$ ha, one $61 \div 90$ ha and two above 90 ha. In most of the farm production profile (Fig. 
$5 b)$ ) is directed at field crops, as many as thirty-two farms. Five farms specialize in horticultural crops, two in fruit and shrubs and eight specializing in animal husbandry.

a)

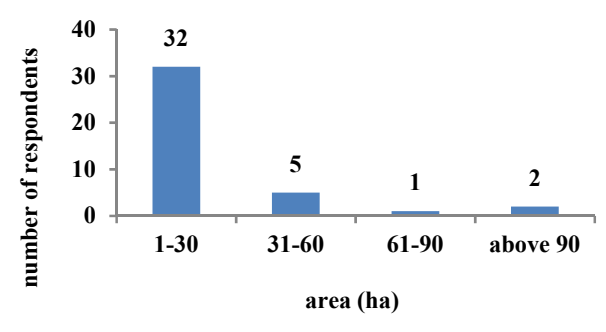

b)

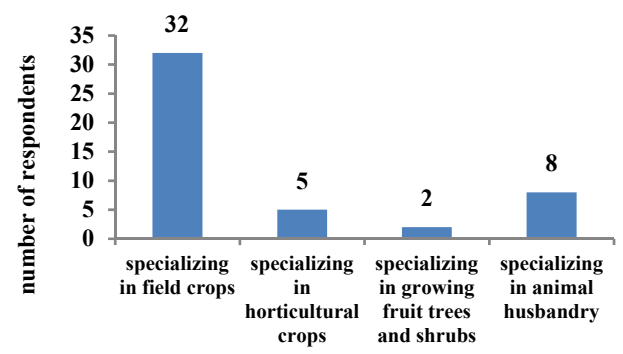

Fig. 5. Share of survey participants relative to: a) The size of the farm given in [ha], b) The production profile of farms

Figure 6a) presents the number of tractors used on the farm. In the Figure 6b) presents data on the planned purchase of a tractor this year by respondents.

a)

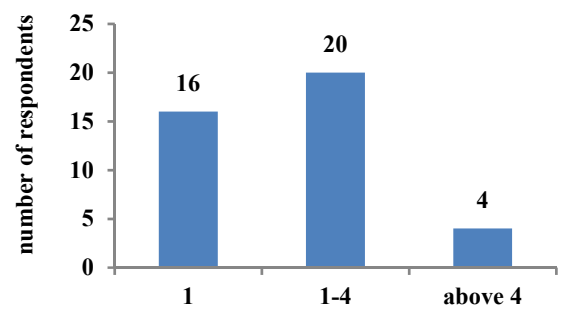

b)

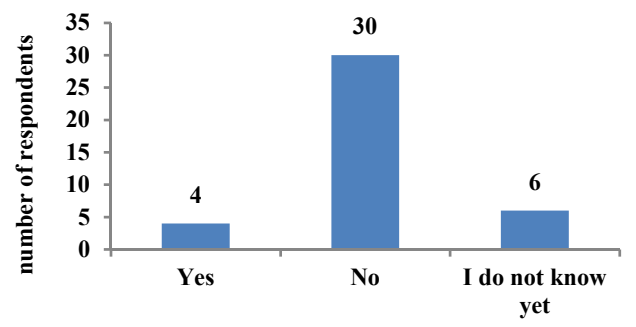

Fig. 6. Share of survey participants relative to: a) Number of tractors used on the farm, b) Planned purchase of a tractor this year

Depending on the profile of the farm and its area, farmers use machines of various power and sometimes need several agricultural tractors. As shown in Figure 6a), up to 4 machines are mostly used in the analysed farms. Among the respondents, sixteen people use one tractor, in the range of 1 to 4 tractors use twenty respondents, and above four tractors, four people.

The analysis of the plans for the purchase of a new tractor in the current year is presented in Figure 6b). The purchase of a new agricultural tractor was confirmed by four people, thirty respondents said that they are not planning to buy, and six respondents have not yet made a decision.

The following figures (Fig. 7 and Fig. 8), the results of the questionnaire regarding purchase preferences of agricultural tractors by respondents and their knowledge of electrically driven tractors are presented.

When buying a new tractor (Fig. 7a)), sixteen people by the engine power, eleven looks at innovative solutions, and twenty-two people looks at the price. According to twenty-seven respondents, the most important criterion that guides the purchase of a new tractor is the comfort of work. It is very good that the majority of respondents are comfortable working. This shows their high awareness of health protection in the work environment. 
Answers to the question on knowledge of electric tractors among farmers is shown in Figure 7b). Fourteen people met with the concept of electric tractors, but only three knew what this type of drive consists of. Most respondents, that is twenty-six people met with this issue for the first time.

a)

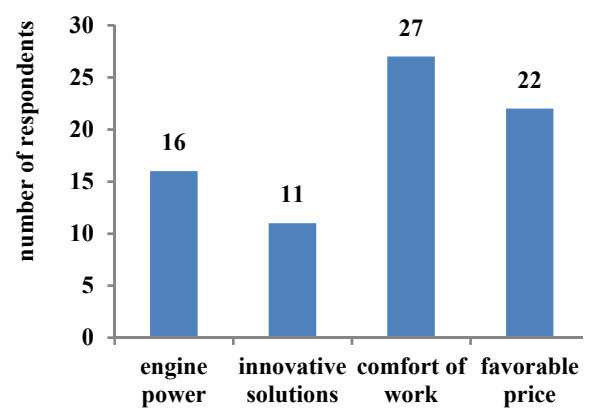

b)

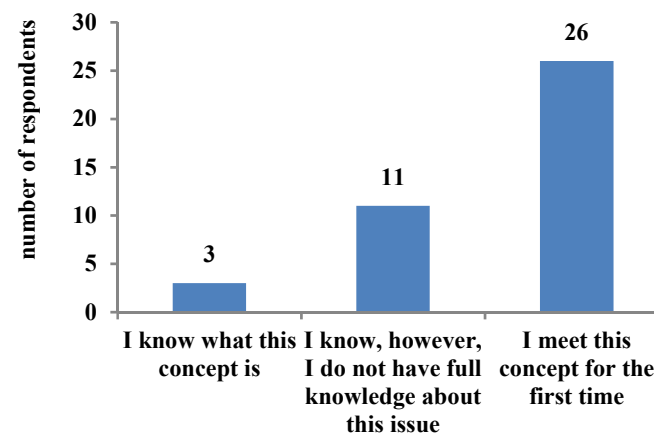

Fig. 7. Share of survey participants relative to: a) Categories that the respondents follow when buying a new tractor, $b$ ) Knowledge about electric tractors

Response to the question about the feelings of respondents in connection with investments concerning the introduction of agricultural electric tractors for use are presented in Figure 8a). For sixteen respondents, this investment is extremely useful and necessary for farms, for eight the investment is unnecessary due to the purchase of traditional tractors. Eleven people have no opinion on the subject, while five people had different opinions. They complained about the lack of specific information about electric tractors, the poor range of their batteries and too high price for tractor that can work only a few hours.

a)

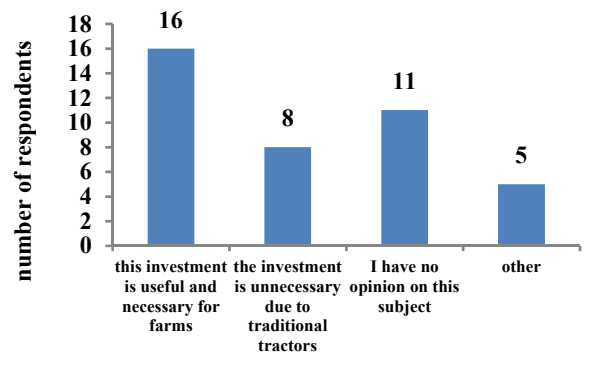

b)

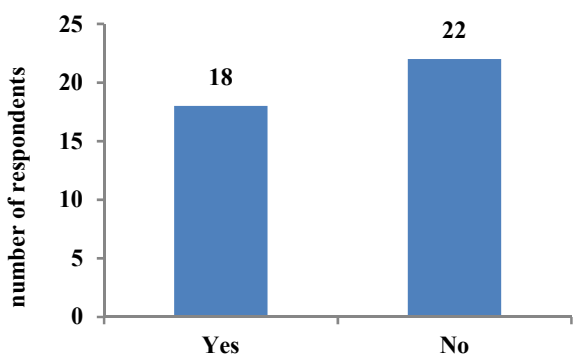

Fig. 8. Share of survey participants relative to: a) Respondents' feelings caused by the investment involving the introduction of electric tractors, b) Decision to buy an electric tractor

Asking the respondents the question "Would you decide to buy an electric tractor?", the authors of the survey expected a negative answer, due to the earlier answers about buying a new tractor, the majority of respondents did not plan to buy a new machine (see the results in Figure 6b)). The result turns out to be different. 18 people have expressed a desire to buy an electric tractor. This is a surprising result and can be an example of the fact that Polish farms are ready and open to implement the concept of electro mobility in agriculture. 


\section{Conclusions}

In the case of electric tractors, in order to be able to talk about a real competition for diesel tractors, they would have to provide a full working day without interruption to recharging. Current solutions that allow only a few hours of work are sufficient only for orchards or green-houses. Moreover, analysing the answers of the respondents when asked whether they are planning to buy a new tractor in the near future, the majority, as many as $75 \%$ of respondents replied firmly - no. This is due to the fact that they have already invested in machines with a traditional drive. However, This does not mean, that electric-powered tractors are a distant future on farms. They are an optimistic herald of changes in the market moving towards the environmental performance and energy efficiency of farms, and the elimination of current restrictions is probably a matter of a few years. John Deere expects that the electric motors will require much less maintenance than a diesel engine [16]. They will also provide and last longer [16].

The decision on whether to invest in an electric tractor is a decision that everyone should take on their own. If someone needs a zero-emission ecological tractor for horticultural or greenhouse works, the choice may seem right, and guaranteeing a significant increase in demand for electric tractors should prompt domestic and foreign investors to build an industry that generates electric vehicles and their components in Poland. As was shown at the beginning of the work (Table 1), Poland is one of the leading countries in terms of employment in this sector.

\section{References}

1. S. Pukalskas, A. Rimkus, M. Melaika, R. Peceliunas, Comparison of conventional and hybrid cars exploitation costs. Advances in Science and Technology Research Journal, 12, 1, 221-227 (2018)

2. T. Skrucany, V. Harantova, M. Kendra, D. Barta, Reducing energy consumption by passenger car with using of non-electrical hybrid drive technology. Advances in Science and Technology Research Journal, 11, 1, 166-172 (2017)

3. D. Barta, M. Mruzek, R. Labuda, T. Skrucany, L. Gardyński, Possibility of increasing vehicle energy balance using coasting. Advances in Science and Technology Research Journal, 12, 1, 228-235 (2018)

4. J. Caban, P. Ignaciuk. Technical-economic aspects of CNG gas usage in buses of urban communication. Engineering For Rural Development, Jelgava, Latvia, 23.-25.05.2018, 2129-2133 (2018)

5. D. Barta, M. Mruzek, Factors influencing the hybrid drive of urban public transport buses. Management Systems in Production Engineering, 4(20), 213-218 (2015)

6. J. Dizo, M. Blatnicky, Use of multibody system dynamics as a tool for rail vehicle behaviour diagnostics. Diagnostyka, 17(2), 9-16 (2016)

7. T. Skrucany, J. Gnap, The effect of the crosswinds on the stability of the moving vehicles. Applied Mechanics and Materials, 617, 296-301, (2014)

8. G.P. Moreda, M.A. Munoz-Garcia, P. Barreiro, High voltage electrification of tractor and agricultural machinery - A review. Energy Conversion And Management, 115, 117131 (2016)

9. F. Bauer, P. Portes, D. Slimarik, J. Cupera, M. Fajman, Observation of load transfer from fully mounted plough to tractor wheels by analysis of three point hitch forces during ploughing. Soil \& Tillage Research, 172, 69-78 (2017) 
10. J. Engstrom, O. Lagnelof, Battery electric autonomous agricultural machine Simulation of all operations on a Swedish farm. Land, Technik Ageng 2017: The Forum For Agricultural Engineering Innovations (VDI-MEG 2017), VDI Berichte, 75th Conference of LAND, TECHNIK - AgEng 2017, Hannover, Germany, Nov. 10-11, 2017, 2300, 15-22 (2017)

11. T. Tunka, J. Cupera, The engine combustion analysis of newly developing diesel tractor engine Zetor Z1727 with Common-Rail system in a first firing week. $22^{\text {nd }}$ International PhD Students Conference, Mendel Univ, Fac Agron, Brno, Czech Republic Nov. 11-12, 2015, Mendelnet 2015, Edited by: Polak O., Cerkal R., Belcredi N.B., 562-567 (2015)

12. R.O. Magalhaes, M.V. da Assuncao, J.P.M. Santos, E.V. da Silva, L.D.G. Ferreira, R.R. Magalhaes, D.D. Ferreira, Review on applications of electric vehicles in the countryside. Ciencia Rural, 47, 7, 1-9 (2017)

13. M. Tomasikova, M. Tropp, T. Gajdosik, L. Krzywonos, F. Brumercik, Analysis of transport mechatronic system properties. $12^{\text {th }}$ International Scientific Conference of Young Scientists on Sustainable, Modern and Safe Transport, High Tatras, Slovakia, May 31-Jun 02, 2017, Edited by: Bujnak J., Guagliano M., In: Procedia Engineering, 192, 881-886 (2017)

14. B. Mcfadzean, L. Butters, An investigation into the feasibility of hybrid and all-electric agricultural machines. Scientific Papers-Series A-Agronomy, 60, 500-511 (2017)

15. J. Šujica, Fend pioneering with electric tractor. https://plugin-magazine.com/driving/ fendt-pioneering-with-electric-tractor/

16. F. Lambert, John Deere unveils latest all-electric tractor prototype for zero-emission agriculture. https://electrek.co/2016/12/05/john-deere-electric-tractor-prototype/

17. J. Scott, Improving tractors, implements with electrification. https://www.agriculture .com/machinery/tractors/improving-tractors-implements-with-electrification

18. J. Zawieska, J. Pieriegud, Smart city as a tool for sustainable mobility and transport decarbonisation. Transport Policy, 63, 39-50 (2018)

19. E. Siemionek, M. Dziubiński, Testing energy consumption in the trolleybus and the bus on a chosen public transport line in Lublin. Advances in Science and Technology Research Journal, 9(26), 152-160 (2015)

20. M. Dziubiński, A. Drozd, M. Adamiec, E. Siemionek, Energy intensity of the electric vehicle. Advances in Science and Technology Research Journal, 11(4), 81-84 (2017)

21. http://www.credenceresearch.com/report/farm-tractors-market

22. http://www.axema.fr/EspacePresse/Lists/Publications/AXM_RE-EN_2015_BD.PDF Economic Report 2015 